their father's disregard for 'No trespassing' signs during family walks, and the consequent confrontations with farmers and landowners. This is an instance of how Wallace's science (in this case, what we now refer to as biogeography) was inextricably embedded in his experiences, and within social and political issues. These cannot be removed to leave the 'bare ideas' behind - they simply would not have existed without them.

Wallace's 1858 paper 'On the tendency of varieties to depart infinitely from the original type' was famously read at the same Linnaean Society meeting as Darwin's hastily penned description of natural selection, in a gentlemanly resolution of the question of priority. Infinite Tropics contains more technical papers than The Alfred Russel Wallace Reader, but this one is rightly central to both collections. A close reading of Wallace's paper reveals two interesting differences in emphasis between it and Darwin's writing of the same era.

First, Wallace stressed competition in relation to the environment (whether organic or inorganic) and between species, rather than the interspecific competition, or "ten thousand wedges", which forms a major part of Darwin's On The Origin of Species and has retrospectively been defined as its crucial argument. In this respect, Wallace is more responsible than Darwin for the layperson's understanding of evolutionary factors a struggle against predators rather than against one's fellow-species.

The second difference is that Wallace emphasizes the distinction between domestic and natural varieties. The latter are defined for him by the organism's need for the variant characteristic, its competitive advantage against other varieties, and (in 1858 at least) its strengthening through use. Together these factors produced an irreversible directionality in the genesis of new varieties in nature. Darwin, meanwhile, although he agreed with all these points individually, preferred to stress the similarities between natural and domestic variants in the construction of his argument. Readers were prepared for the idea that nature might select by comparison to the acts of a pigeon breeder, amongst other homely examples. Here, Darwin's version subtly but powerfully altered the reception of his argument, making selection more anthropomorphic and less environmental - less a product of the land, as Wallace would have had it.

The geologist Charles Lyell, the botanist Joseph Hooker and Darwin all failed to pick up on these differences while discussing the presentation of Darwin and Wallace's work as simultaneous discovery. This corroborates the arguments of recent historians (Gillian Beer, Adrian Desmond, James Moore and Robert Young) that Darwin's ideas were by no means as clear-cut as the authors of the 'new synthesis' - and biology textbooks - would have us believe. Wallace's 'problematic' interests and perspectives are revealed by these excellent anthologies (especially Camerini's) to be key to understanding the mid-nineteenthcentury debates about evolution in their true cultural complexity.

Charlotte Sleigh is at the Centre for History and Cultural Studies of Science, Rutherford College, University of Kent at Canterbury, Canterbury CT2 7NX, UK.

\section{I am loved, therefore I think}

\section{The Cradle of Thought: Exploring the Origins of Thinking \\ by Peter Hobson}

Pan Macmillan: 2002. 291 pp. $£ 20$

\section{Simon Baron-Cohen}

How does the mind grow? This is a question that has exercised some of the best minds over the centuries, and Peter Hobson joins this laudable effort to try to answer it with his new book The Cradle of Thought. Hobson is critical of the classical piagetian answer, because it focuses on the child as a solitary mini-scientist, testing his or her current (and usually mistaken) theory in the laboratory of the sand-pit or the playroom. Quite correctly, Hobson points out the limitations of this essentially asocial perspective on cognitive development. Instead, he argues that the origins of all thought lie in social relations.

This line of argument has a long and noble pedigree. Marx suggested that all thought was a product of social and economic relations, and the Russian psychologist Lev Vygotsky (no doubt influenced by his own post-Revolution society) proposed that learning is typically facilitated by one's peer group. But Hobson's slant on the social origins of the mind comes not from this socialist framework so much as his psychoanalytic background.

Sigmund Freud, and later John Bowlby,

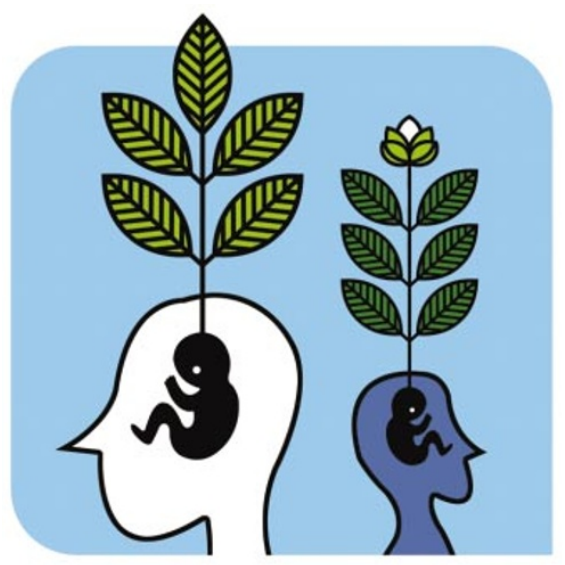

argued convincingly that one's earliest attachments with 'significant others' shape the development of the mind. Usually the 'attachment figure' is an adult caregiver, but - as demonstrated in the famous case of the orphaned Jewish victims of the Nazis studied by Anna Freud - in the absence of a parent figure, attachments can be equally strong towards a peer or sibling.

There is little doubt, from the thousands of experimental studies of the effects of the quality of attachment, that such early relationships are strongly deterministic of later emotional well-being. No one today (if they ever did) now questions whether abuse and neglect are bad for your later mental health - they invariably are. Hobson also reviews the intricate experiments by such pioneer child psychologists as Colwyn Trevarthen and Daniel Stern showing the exquisite sensitivity human infants have to their caregiver's emotional states and behaviour; how the 'dance' between a mother and her infant can become derailed by events such as postnatal depression.

It is not surprising that early emotional factors predict later ones. The surprise from this line of research is that early emotional factors partly predict cognitive outcomes IQ, for example, and school attainment measures such as literacy. Reviewing the large body of evidence leads Hobson to conclude that all the unique aspects of human thought, including our capacity to use symbols, are social in origin.

$\mathrm{He}$ is careful to acknowledge that genetic and neurobiological factors can prevent a child from emotional engagement with others, when discussing children with the psychiatric condition of autism, with whom normal social relations are not possible. But he also reviews studies suggesting that forms of deprivation can also lead to autism, such as the sensory deprivation of congenital blindness or the emotional deprivation of children discovered during the past few years in Romanian orphanages.

There is much to admire in this immensely readable book, and Hobson is both an outstanding scholar and passionate about his subject. His human and clinical concern for people comes through clearly in his writing, and his book will be a welcome contribution to the debate in cognitive development. I part company with him on three fundamental issues, though.

First, just because some aspects of thought (such as empathy) clearly have emotional origins doesn't mean that all human thought is social in origin. How, for example, does an autistic 'savant' who can compute all prime numbers at lightning speed do this with little if any experience of emotional intimacy? This suggests to me that some aspects of cognition have little to do with social relations.

Second, although Hobson acknowledges 
that genetic factors might partly determine the mind, he attacks the idea of the existence of innate, pre-programmed cognitive modules. I find this argument incoherent. Modularity theorists do not suggest that modules can function and develop without experience any more than geneticists believe that genes can function without an environment. If you accept that there are genes that can build brain structures, why not at least remain open to the possibility that genes can build mental modules?

And finally, while Hobson's groundbreaking studies of individuals with congenital blindness, or Michael Rutter's seminal studies of the Romanian orphans, have shown us that the effects of early deprivation can resemble autism, might this be no more than a surface similarity? We should be careful not to assume that just because two church bells are ringing simultaneously they are causally connected by the same rope.

Hobson's own important studies of emotion perception in autism are nicely described in this book, and in many ways were ahead of their time. There is no question that this major figure in the field of developmental psychopathology will continue to stimulate healthy debate.

Simon Baron-Cohen is in the Department of

Experimental Psychology, University of

Cambridge, Downing Street, Cambridge

CB2 3EB, UK.

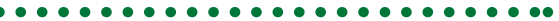 \\ Improving on humanity?}

\section{Redesigning Humans: Our}

Inevitable Genetic Future

by Gregory Stock

Houghton Mifflin: 2002. 288 pp. \$24

\section{Robert Winston}

William Thomson (later Lord Kelvin) entered Glasgow University at the age of ten, achieved a first in mathematics at Cambridge, published over 600 scientific papers, and became president of the Royal Society in 1890 . He was a pioneering physicist but, like many competent scientists, he was not a brilliant futurologist. Less than ten years before the Wright brothers flew he said: "I can state flatly that heavier-than-air flying machines are impossible." And he once claimed: "X-rays will prove to be a hoax." Given his views on creationism - "overwhelming strong proofs of intelligent and benevolent design lie around us" - one wonders what he might of made of the implications of modern molecular biology.

Our imperfect knowledge of DNA and the human genome raises more unanswered questions than any other aspect of science. People from all walks of life are nervous

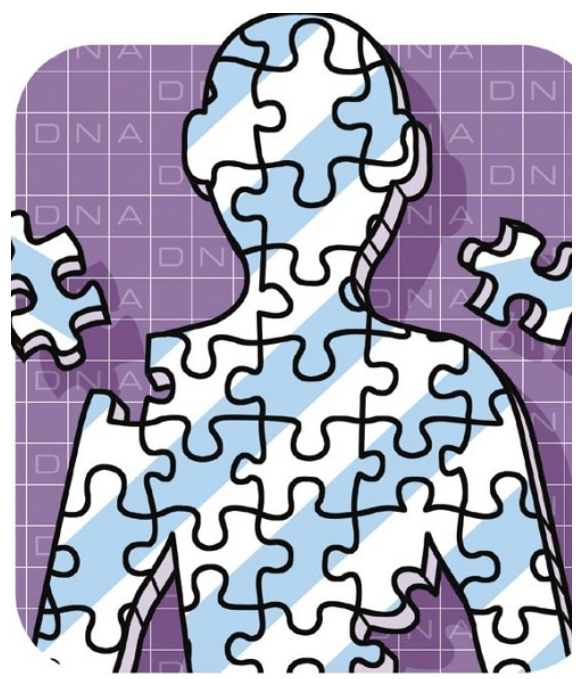

about the implications of genetic knowledge and genetic manipulation. The heat of debates on reproductive cloning and genetic testing is evidence of the anxieties of so many people. This carries a salutary lesson. If scientists misrepresent or exaggerate the power of these technologies, or are not scrupulously objective, the pursuit of knowledge is threatened. Unlike those relatively uncritical golden days of Lord Kelvin, our pronouncements will have a profound effect on public perception and the health of science, and thus on society.

One oddity about the debate on the interface between genetics and human embryology is that it has often been wrongly focused. Given the risks of producing an abnormal child - and the litigation that would ensue - I cannot believe, for example, that human cloning will be attempted in any significant way. So the crucial issue is the use of transgenic technology. We can make transgenic animals with relative ease; and we can add, modify or knock out genes in intact mammals. The key question is whether these technologies might be used in humans.

Gregory Stock of the UCLA School of Medicine bravely predicts this future for humanity. He is undeterred by the poor record of futurology, believing that it is only a matter of time before human germline modification becomes a fact. His new book, Redesigning Humans: Our Inevitable Genetic Future, is a distillate of opinions he has publicly expressed for some years. He writes with a clear, lucid style that lends plausibility to his views. Yet many readers will wonder whether the assertions about reproductive technology that are crucial to his argument are accurate. For example, he makes claims for the profound global impact of contraceptive technology. Without the worldwide access to birth control, Stock asserts, birth rates would not be falling. But this does not stand up to scrutiny. Falling birth rates are more to do with improved social infrastructure better hygiene, education, decreasing infant mortality and changing social attitudes than with his technocentric approach.
People will want genetic choice, claims Stock. He seems to believe that human nature will change so much that assisted reproduction could replace procreation on the hearth-rug. We have, he says, now accepted much of what is ethically debatable in the area of genetic choice, by using preimplantation genetic diagnosis (PGD) in embryos. PGD will be "in the vanguard of genetic choice, at least for the next couple of decades," Stock contends. But this is not likely to be even approximately true. Only one-fifth of embryos resulting from in vitro fertilization are viable; many, if not most, human embryos are frequently aneuploid or have other cellular abnormalities that are probably incompatible with development. Mosaicism is extremely common - perhaps $75 \%$ of morphologically normal human embryos have at least one or two aneuploid cells at around the eight-cell stage. Biopsy of such cells will be likely to give useless clinical results, and PGD biopsy of a normal cell in such an embryo may lead to false diagnosis.

So if Redesigning Humans is wide of the mark when discussing technology that has already been used for over a decade, why should futuristic comments about germline modification be any closer to the truth? Stock rightly observes that current transgenic manipulation is unpredictable, but he seems overimpressed by recent developments. It will be relatively easy to introduce auxiliary chromosomes into the germ line, and they could carry large chunks of DNA without the limitations mostly imposed by conventional gene vectors. Genes on these chromosomes could be introduced without changing other parts of the genome and could incorporate a mechanism for terminating expression to improve safety.

Stock argues that this strategy could eventually be used to enhance "desirable" characteristics for single generations and that outdated auxiliary chromosomes could be jettisoned for newer, more up-to-date models. Work in mice, he feels, suggests that this could eventually be done without human harm. But many geneticists will feel queasy; the potential for gene imbalance is huge and the change in phenotype unpredictable.

This is an important debate, but a real moral perspective is missing in this mostly engaging book. Stock favours human genetic enhancement. He quotes James Watson: "If we can make better humans... why shouldn't we?" And he is scathing about the conservative attitude of notable scientists such as French Anderson. To many readers elsewhere, his view will seem centred on privileged North America, taking little cognisance of the appalling inequalities in his and their society which would be increased by this manipulation. We are as much the product of our environment as of our genes, and much should be done first about the 